\title{
ANTROPOARQUEOLOGÍA EN LA MAGDALENA. EL ESTUDIO DE RESTOS ÓSEOS HUMANOS: CIENCIA TÉCNICA Y MÉTODO ENTRE LA MULTI Y LA TRANSDISCIPLINARIEDAD
}

\author{
César HERAS MARTÍNEZ 1, 2,3 \\ Virginia GALERA OLMO ${ }^{2,3}$
}

\section{Resumen:}

La interacción entre las Antropologías y la Arqueología se muestra como una necesidad básica a la hora de interpretar los distintos parámetros que concurren en los estudios de los procesos naturales y culturales de las sociedades del pasado. Tras años de asentamiento y difusión, primero de los estudios multidisciplinares y más actualmente de los interdisciplinares, es necesario dar una nueva vuelta de tuerca a estos distintos estudios y a su forma de enfrentarnos a ellos, aportando una visión transversal a los problemas planteados, conformando una visión transdisciplinar del objeto de investigación.

\section{Palabras clave:}

Antropología-Antropologías; Arqueología; Tafonomía; Tanatología; Ritual funerario; La Magdalena-Alcalá de Henares

\section{Abstract:}

The interaction between the Archaeology and the different branches of Anthropology is shown as a need in order to interpret the various parameters that occur in the studies of the natural and cultural processes of the past. After years of settling and diffusion, first by multidisciplinar studies and then the interdisciplinar ones, is once again necesary to create a new way to work with this processes, one that allows a transversal vision of the matter of study, creating a transdisciplinar view of the investigated issue.

\section{Key words:}

Anthropology-Anthropologies; Archaeology; Taphonomy; Thanatology; Burial ritual; La Magdalena-Alcala de Henares

1 Trébede, Patrimonio y Cultura, S.L.

2 Universidad de Alcalá (UAH)

3 Instituto Universitario de Investigación en Ciencias Policiales (IUICP-UAH)

Revista Otarq - ISSN 2530-4933

Vol. 1 2016, pp. 3-27 


\section{Introducción: Antropoarqueología versus arqueoantropología}

Etimológicamente, la palabra "antropología" se deriva de la raíz griega anthropo- ("hombre") y de la terminación nominal -logia ("ciencia"). Su significado literal es, por tanto "la ciencia del hombre". La Antropología combina en una sola disciplina los enfoques de distintas ciencias, tanto biológicas como sociales. Sus problemas se centran, por un lado, en el hombre como miembro del reino animal $y$, por otro, en el comportamiento del hombre como miembro de una sociedad (Beals y Hoijer, 1978: 5). El antropólogo no se limita a un grupo particular de hombres o a un periodo dado de la historia. Por el contrario, se interesa tanto por las formas pretéritas del hombre y de su comportamiento, como por las actuales.

Partiendo de estos principios, si seguimos la clasificación de la UNESCO, la Antropología física (disciplina 2402), el primero de los ejes que componen nuestro encuadre científico, quedaría integrada dentro del campo de las ciencias de la vida. Por su parte, la Antropología cultural, la Etnografía/Etnología y la Antropología social (disciplinas 5101 a 5103, respectivamente) quedan integradas dentro del campo de la Antropología. Sin embargo, la Arqueología no aparece sino dentro del campo de la Historia, aunque no con el mismo rango disciplinar de las anteriores, sino como un subapartado disciplinar de las Ciencias auxiliares de la Historia (en este caso 550501), dándole el mismo rango que, por ejemplo, el estudio sobre la cerámica (550502).

Esta situación parte de la definición tradicional dada a la Arqueología, como la "ciencia que estudia lo que se refiere a las artes, a los monumentos y a los objetos de la antigüedad, especialmente a través de sus restos" (RAE, 22ª edición, 2014). En ella se prima el elemento material e incluso el estilístico, en detrimento de aquello que los profesionales han venido interpretando, al menos desde los últimos decenios, en el sentido de que la Arqueología pretende reconstruir las formas culturales del pasado, y rastrear su crecimiento y desarrollo en el tiempo, a la par que imbrica todo ello con los distintos procesos de desarrollo y adecuación biológicos del ser humano.

Bajo estas premisas, la comprensión del fenómeno humano en sus vertientes tanto física como socio-cultural, atendiendo tanto al sujeto, como al objeto, y añadiendo la variable que ofrece el mundo de lo inmaterial, clave para la correcta interpretación del ser humano en todo su contexto, se convierte en el nuevo modelo paradigmático para la global interpretación del hombre y sus circunstancias, todo ello visto a la par desde una perspectiva de hitos sincrónicos entramados en un eje diacrónico.

La visión histórica, eminentemente diacrónica, aporta la secuenciación necesaria para la interpretación de los procesos de desarrollo, tanto evolutivos como involutivos, conformando el tercer eje del armazón del fenómeno humano, 
junto con la antropología física y la socio-cultural, y todo ello interrelacionado, primeramente con el entorno medioambiental, y posteriormente con cuanto modelo disciplinar aborde aspectos del desarrollo humano, tales como la antropología del derecho, la filosofía, la economía, la política, etc.

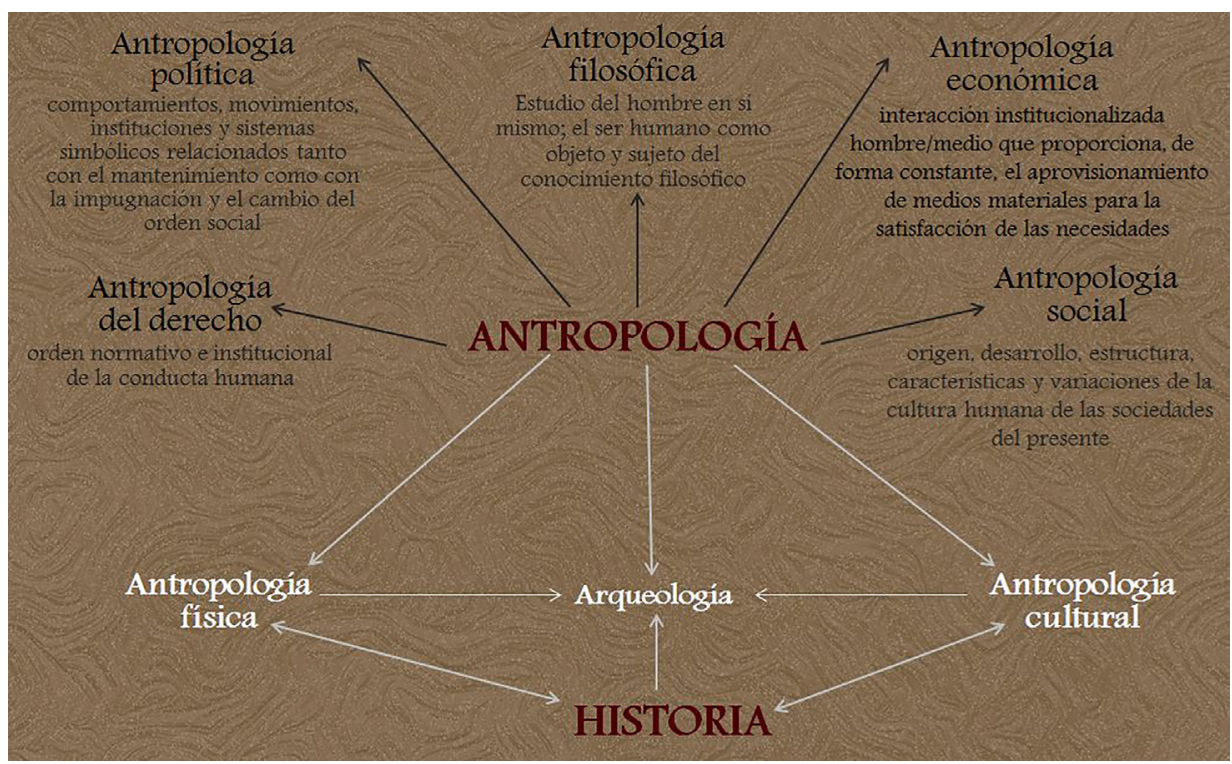

Fig. 1. Interrelación entre la/s Antropología/s y la Arqueología, esta última cada vez más relacionada con el sujeto aunque sin olvidar el objeto.

Edgar Morin, en su obra Introducción al pensamiento complejo (2009) nos habla de trascender las visiones pluridisciplinares o multidisciplinares y las interdisciplinares, que han ido abriendo el camino de la interacción de las diversas disciplinas científicas, tanto físicas como sociales, alcanzando un planteamiento transdisciplinar, entendida tal como una forma de organización de los conocimientos que trascienden las disciplinas de una forma radical. Se ha entendido la transdisciplina haciendo énfasis a) en lo que está entre las disciplinas, b) en lo que las atraviesa a todas, y c) en lo que está más allá de ellas.

La transdisciplinariedad es una concepción relativamente reciente. La propia complejidad del mundo en que vivimos nos obliga a valorar los fenómenos interconectados. Las actuales situaciones físicas, biológicas, sociales y psicológicas no actúan sino interactúan recíprocamente. La descripción del mundo y de los fenómenos actuales nos exige una nueva forma de valoración desde una perspectiva más amplia, con una nueva forma de pensar que reclama encontrar un nuevo paradigma capaz de interpretar la realidad actual. A esto nos lleva la concepción transdisciplinaria. 


\section{Variabilidad biológica del hombre: inferencias espacio-temporales}

La Antropología física es la disciplina científica que estudia la variabilidad biológica del hombre en el espacio y en el tiempo y las causas que producen dicha variabilidad.

Los antropólogos físicos se interesan por las poblaciones humanas, por qué unos grupos son más altos y otros más bajos, por qué difieren en cuanto a la pigmentación de la piel, cuáles son los procesos de crecimiento y desarrollo y qué ocurre cuando se envejece, quiénes fueron los antepasados del actual Homo sapiens y cómo evolucionaron, por qué los simios son sus parientes más próximos o qué grupos sanguíneos o polimorfismos del ADN diferencian a unos grupos de otros o a los distintos grupos de Primates entre sí. En esta disciplina se estudian todos estos aspectos, sin olvidar que el hombre es el resultado de su biología y de su cultura, y desde una perspectiva actual que tiene muy en cuenta los numerosos datos que ofrece el registro fósil, el ADN y los avances tecnológicos.

No se puede olvidar que los conocimientos que aporta la Antropología biológica tienen, en numerosas ocasiones, una aplicación práctica, al poner los resultados de la investigación científica al servicio de la humanidad. Son de destacar las contribuciones al mundo del deporte (Antropología del deporte o Cineantropometría), la salud de las poblaciones (Antropología de la salud y riesgo ocupacional), la "ingeniería", para lograr el máximo ajuste morfo-funcional entre el hombre y su entorno físico de actividad (Ergonomía), la justicia, al intervenir en la resolución de casos forenses (Antropología forense), entre otras.

Esta disciplina ha ido evolucionando con el tiempo, lo mismo que lo han hecho los métodos y técnicas que emplea. Actualmente son numerosas las sociedades antropológicas que engloban a los antropólogos físicos en todo el mundo y son ellas las que dan las pautas tanto en el plano académico como en cuanto a las líneas prioritarias en la investigación científica (Rebato et al., 2005). En España es la Sociedad Española de Antropología Física (SEAF) quién junto con la European Athropological Association (EAA) y la American Association of Physical Anthropologist (AAPA), tienen una mayor influencia sobre los especialistas de este campo científico. Por otro lado, señalar que son múltiples las colaboraciones que en la sociedad actual, tan globalizada, se establecen entre los antropólogos físicos de una determinada institución, con los profesionales de otras disciplinas e instituciones, con el objetivo de intercambiar conocimientos y medios materiales, para resolver, de forma conjunta y con el mayor aprovechamiento de medios, cualquier cuestión de interés científico y/o social. Un claro ejemplo es la estrecha relación del Área de Antropología Física de la Universidad de Alcalá (UAH) con el Instituto Universitario de Investigación en Ciencias Policiales (IUICP) y, con la Empresa Trébede, Patrimonio y Cultura, S.L. Con esta última se viene, desde hace años, investigando y aportando datos sobre las gentes que fueron enterradas en 
diversos yacimientos arqueológicos ubicados en la Comunidad de Madrid, como el de "La Magdalena" y "Empecinado 4" (Alcalá de Henares), o "El Perdido", "El Camino" o "Los Leones" (Torres de la Alameda).

\section{Planteamientos desde la arqueología. El hombre como fenómeno cultural}

La cultura es la característica más distintiva del hombre. Como ya hemos apuntado, la Antropología social y cultural estudia los orígenes y la historia de las sociedades humanas y de sus culturas. Se ocupa de la evolución y el desarrollo de la cultura per se, ya pertenezca a nuestros antepasados o a las sociedades actuales. Se trata de la investigación sobre procesos sincrónicos (que denota el estudio de las sociedades y culturas en un punto dado de su historia) y diacrónico (que denota el estudio de las sociedades y culturas a través del tiempo).

Partimos de la base de nuestra consideración de la Arqueología como una disciplina científica, con ciertas peculiaridades, pero no distintas de las observadas en otras tantas líneas disciplinares.

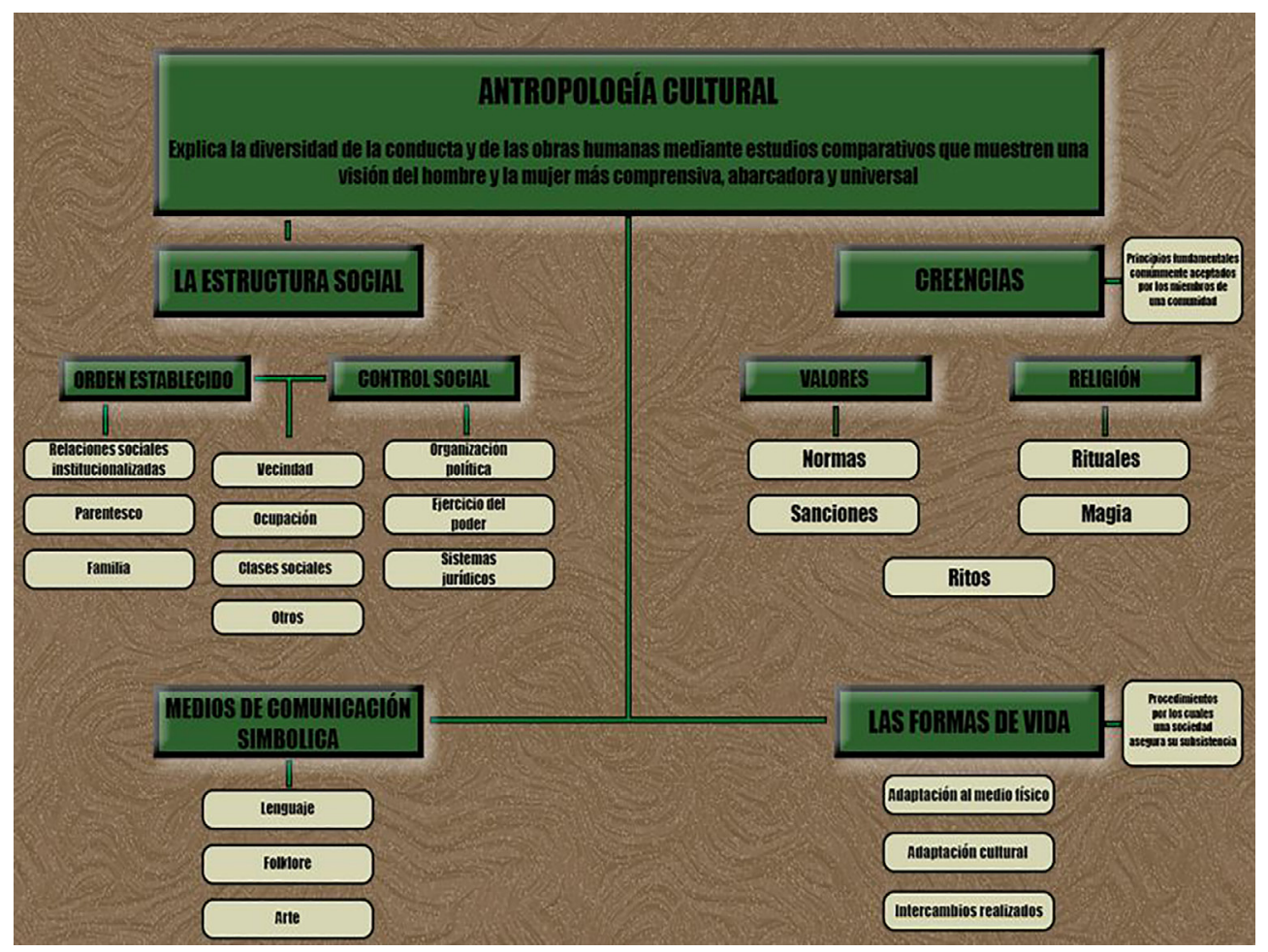

Fig 2. Componentes generales de la Antropología cultural. 
La necesidad de interpretar la Arqueología como ciencia nace como una respuesta rupturista de los planteamientos decimonónicos que asociaban la Arqueología con la descripción de ciertos elementos materiales, altamente significativos bajo dos prismas diferenciados: lo bello y lo raro.

El inicio de los planteamientos científicos para la Arqueología viene, en Europa, de manos de especialistas en diversas disciplinas relacionadas con la Biología/Ciencias Naturales o con la Ingeniería y las minas. En América, amén de estos mismos modelos, y con una visión centrada en el ser humano como fenómeno complejo se desarrolla lo que derivaría en la Antropología cultural.

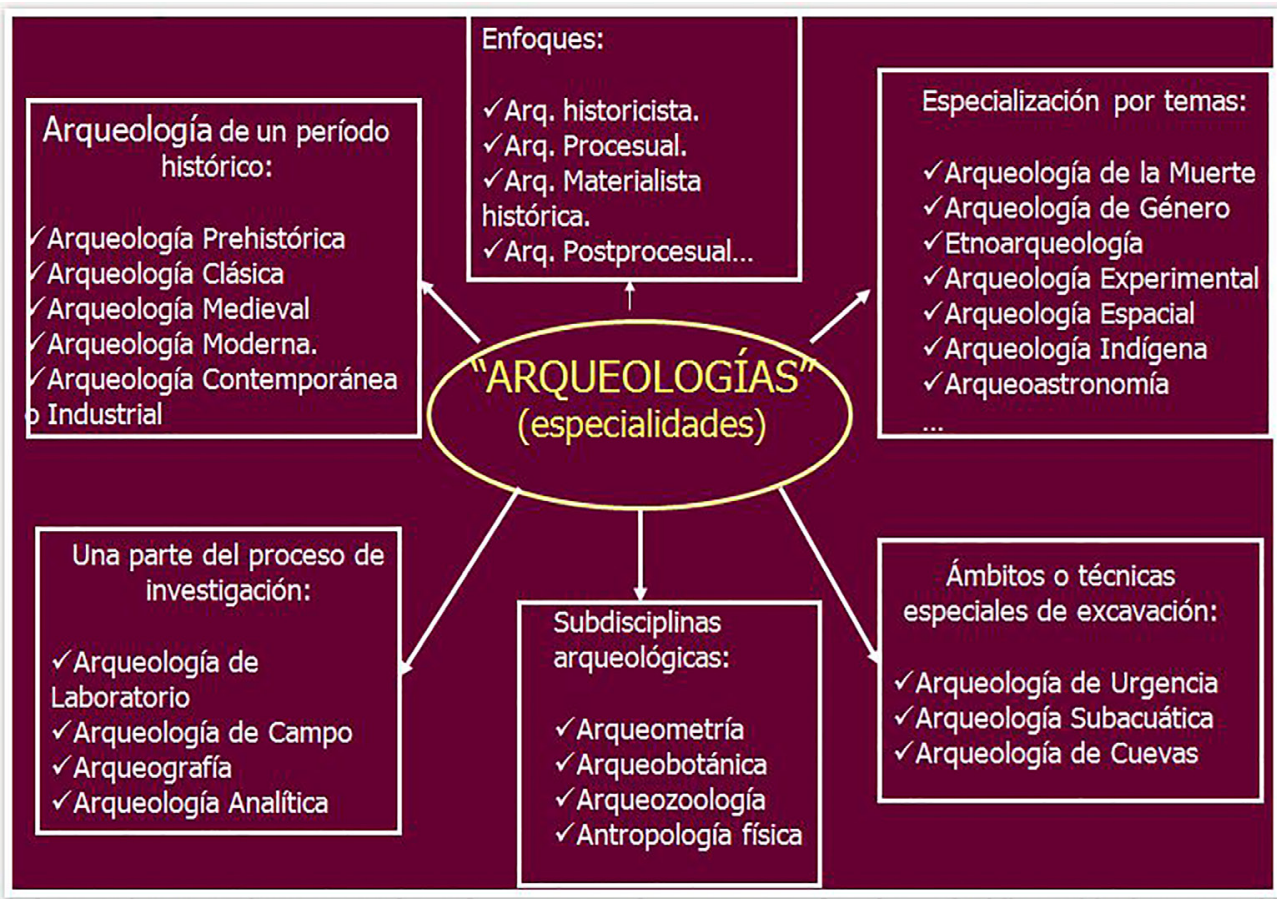

Fig. 3. La Arqueología y las arqueologías: métodos, técnicas y cronologías.

De este modo, la disciplina arqueológica se va desarrollando, dando pie a su interpretación como la ciencia que estudia las artes, los monumentos y los objetos de la antigüedad, especialmente a través de sus restos.

De aquellos momentos a la actualidad, hemos dejado de considerar al artefacto como sujeto y objeto de la investigación. Así, la Arqueología pasa a ser la ciencia que estudia las sociedades antiguas a partir de sus restos materiales. A través del análisis de los objetos y aquellas obras construidas por los pueblos antiguos, esta ciencia puede arribar a conclusiones en torno a su cultura y sus formas de vida. 
Mucho se ha escrito y mucho queda por escribir sobre los planteamientos filósófico-teoréticos subyacentes a cualquier discurso, en el caso que nos ocupa, relacionados con la Arqueología. Se trata de un debate no sólo no solucionado, sino que probablemente carezca de una solución integral e integradora, sobre todo dada la peculiaridad tanto del estudiante como del estudiado.

La Arqueología, entendida como el tiempo pasado de la Antropología cultural, pretende reconstruir las formas culturales del pasado y rastrear su crecimiento y desarrollo en el tiempo.

Definimos la Arqueología, a partir de las propuestas originadas en la segunda mitad del pasado siglo XX, tanto como el campo técnico de estudio como el científico o de conocimientos que se ocupa del estudio de las sociedades y culturas del pasado, a partir de los restos de cultura material y de los datos hallados en el contexto natural y socio-cultural mediante la exploración superficial del terreno y la excavación estratigráfica. La contextualización de los patrones de lo intangible, entrarían en el campo de la Antropología cultural, entre los que destacan los modelos parentales, las relaciones interpersonales y/o intergrupales $y$, muy especialmente, la conceptualización de la dualidad vida/muerte.

Nos mostramos de acuerdo con la apreciación hecha por F. Criado, quien apunta que la Arqueología se debe entender como "la disciplina que estudia, a partir del registro arqueológico, la integración de la cultura material en los procesos sociales de construcción de la realidad" (Criado, 2012: 17).

Las pautas del desarrollo de la interacción entre Antropología cultural y Arqueología quedarían a grandes rasgos reflejadas en el siguiente esquema:

1. De Ciencia $=$ Antropología $\neq$ Arqueología a Ciencia $=$ Antropología $=$ Arqueología

2. Sociedades y Culturas (estudio de grupos)

3. No todo son cacharros

4. Lo Tangible y lo Intangible

5. Exploración integral: entornos-prospección-excavación

6. Multidisciplinariedad Interdisciplinariedad Transdisciplinariedad

Tras el auge y caída de escuelas tales como la procesualista y la postprocesualista y la constatación de las limitaciones de la Arqueología del paisaje, actualmente nos encontramos ante un momento donde en el campo teórico prima el eclecticismo, conjugando diversas tendencias escolásticas con planteamientos de corte bien economicista de base neomarxiana, bien historicista-cultural. 


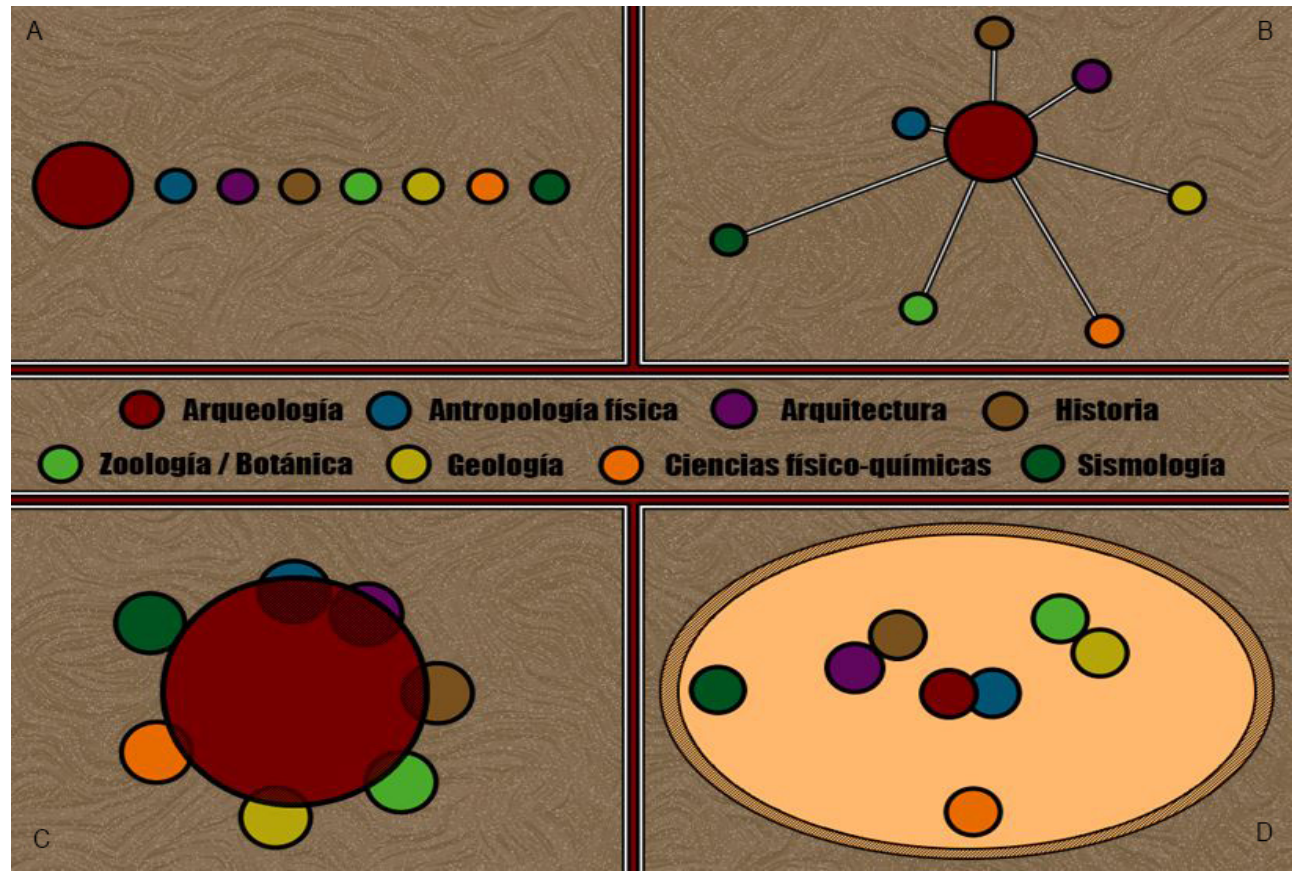

Fig. 4. Variables de los distintos modelos de relación entre las diferentes facies disciplinares. (A) Investigación lineal; (B) Pluri/multidisciplinar; (C) Interdisciplinar; (D) Transdisciplinar.

\section{La Arqueología de la muerte}

El registro arqueológico no se compone de símbolos, palabras o conceptos, sino de restos materiales y distribuciones de materia. El único modo de poder entender su sentido es averiguar cómo llegaron a existir esos materiales, cómo se han modificado y cómo adquirieron las características que vemos hoy (Binford, 1988: 23).

La llamada "Nueva Arqueología" planteó por primera vez la necesidad del registro sistemático funerario como fuente de información privilegiada sobre la estructura social y la cultura, yendo más allá de los tradicionales enfoques descriptivos, constituyendo la génesis de lo que en estos últimos decenios se ha dado en denominar "Arqueología de la muerte" o "Arqueología funeraria". El documento funerario es un producto material de la acción social mediatizada por la intencionalidad de su constitución discursiva, incluso en lo que se refiere a la información paleodemográfica y paleopatológica, dos rasgos de la mortalidad que aparentemente son independiente de la intencionalidad discursiva del ritual funerario (Ruiz Zapatero y Chapa, 1990; Chapa, 1991; 2000). 
La Arqueología de la muerte estudia e interpreta los enterramientos en una doble vertiente: una material (producto material del comportamiento social) y otra simbólica (aspectos ideológicos del comportamiento humano), a la par que se imbrica directamente con los distintos procesos propios de la Antropología física.

Podría quedar configurada en cinco áreas de estudio, aunque sin olvidar que, a su vez, queda integrada en un contexto mayor medioambiental y socio-cultural:

- Área funeraria

- La tumba

- Tipo de enterramiento (primario/secundario)

- El cuerpo (inhumado/cremado...)

- El ajuar

- Ritual mortuorio/rituales postmortem

A todo ello habría que añadir las distintas posibilidades que ofrecen variables tales como la definición de las distintas partes de una tumba/sepultura, los tipos de enterramiento o de depósito, sexo y edad del individuo, posición del cuerpo, patologías, etc., elementos básicos para una comprensión más integral del fenómeno funerario (Almela, 2012).

Igualmente, hay que considerar las distintas formas disciplinares que se han dado para interpretar la problemática arqueológica en general y, más concretamente la fenomenología de la muerte o Arqueología funeraria.

Los primeros trabajos desarrollados siguieron una sistemática de carácter lineal, donde las distintas disciplinas desarrollaban sus trabajos específicos, aunque sin entrar en considerar la necesidad de ni siquiera apoyarse o contemplar la existencia de otras maneras de enfrentarse al estudio de un tema concreto.

La llegada de los primeros análisis multidisciplinares abrió las expectativas de investigación, pero siempre contando que una de ellas (en el caso que nos compete la Arqueología), se erigía como núcleo central de la investigación, empleando las posibilidades que ofrecían otras disciplinas de un modo tangencial, haciendo uso exclusivamente de algunos de los resultados obtenidos $\mathrm{o}$, como mucho, incorporando en los estudios un apéndice o un capítulo con la información más interesante para el discurso arqueológico.

No es sino con la llegada de nuevos modos teóricos y el desarrollo de diversos campos científicos, cuando comenzamos a valorar el trabajo integrado entre diversas disciplinas, llegando a integrarlos en un discurso común, aunque sigan primando, a la hora de acometer las interpretaciones de los eventos estudiados, las que devienen 
del discurso arqueológico. Aquí es donde los modelos teóricos de corte histórico y/o antropológico comienzan a tener claras confluencias.

\section{Categorias generales Esfera de análisis Inferencias}
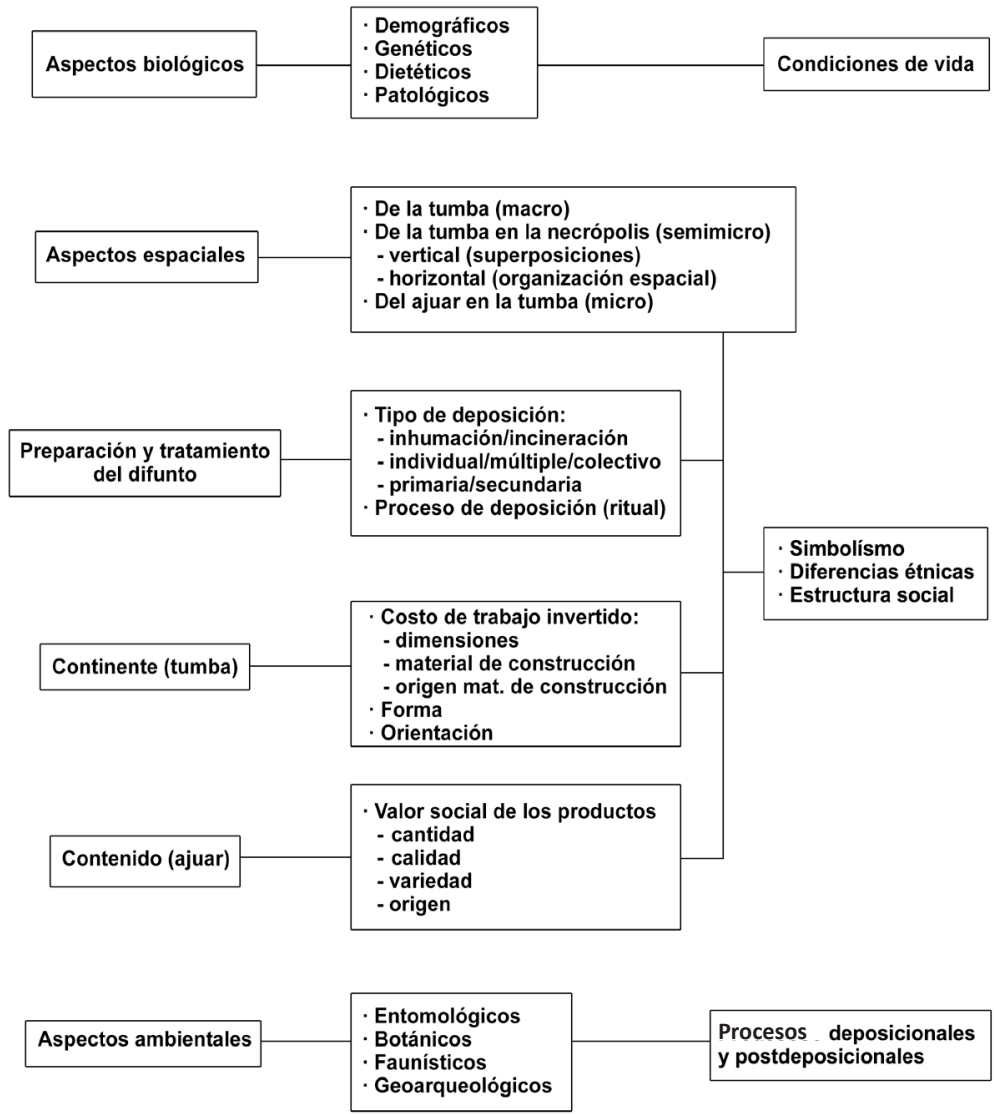

Fig. 5. Arqueología de la muerte: elementos y variables de estudio e interpretación.

Por último, en estos últimos decenios viviendo una verdadera interacción, y lo que es más importante en rango de igualdad, entre una gran cantidad y variedad de disciplinas científicas, aunque sin embargo, no dejan de ser mayoritarios los trabajos que se desarrollan en cualquiera de los anteriores modos de acometer un estudio de estas carácterísticas. Los modelos transdisciplinares plantean la resolución de un problema a través de las distintas interpretaciones disciplinares, empleando todas ellas de una forma paritaria como técnica y disciplina, siendo los resultados los que se interpretan científicamente desde una base que, consideramos ha de ser de corte plenamente antropológico. 


\section{Vida y muerte en el yacimiento de La Magdalena}

El yacimiento de La Magdalena (Heras et alii, 2014) es una fuente extraordinaria de información sobre la biología de los grupos humanos que allí fueron enterrados. A continuación se exponen algunos de los resultados obtenidos hasta el momento, la mayoría de ellos basados en varias publicaciones sobre el tema (Cabrera et al., 2014; Díaz et al., 2014; Gómez et al. 2011, 2014; Pacheco et al., 2010; Rivilla et al., 2014).

\section{Tafonomía}

La Tafonomía informa sobre los acontecimientos o procesos que le han ocurrido a un cadáver desde que el individuo murió hasta que fue descubierto y excavado. Las lesiones tafonómicas son debidas a diversos factores (figura 06) y se presentan como alteraciones del hueso en las que se observa con toda claridad que hay una ausencia de respuesta ósea a la misma. Algunas son debidas al lugar de enterramiento ya que dependen de factores como el tipo de tierra, material del féretro, si es que existió, la ropa del cadáver, etc. En otras ocasiones, la causa es la acción de los seres vivos, como animales carnívoros o roedores, raíces de plantas, hongos, etc. Las fracturas postmortem son muy valiosas ya que pueden informar sobre desmembramientos, mutilaciones y desarticulaciones. También hay que tener en cuenta la acción antrópica.

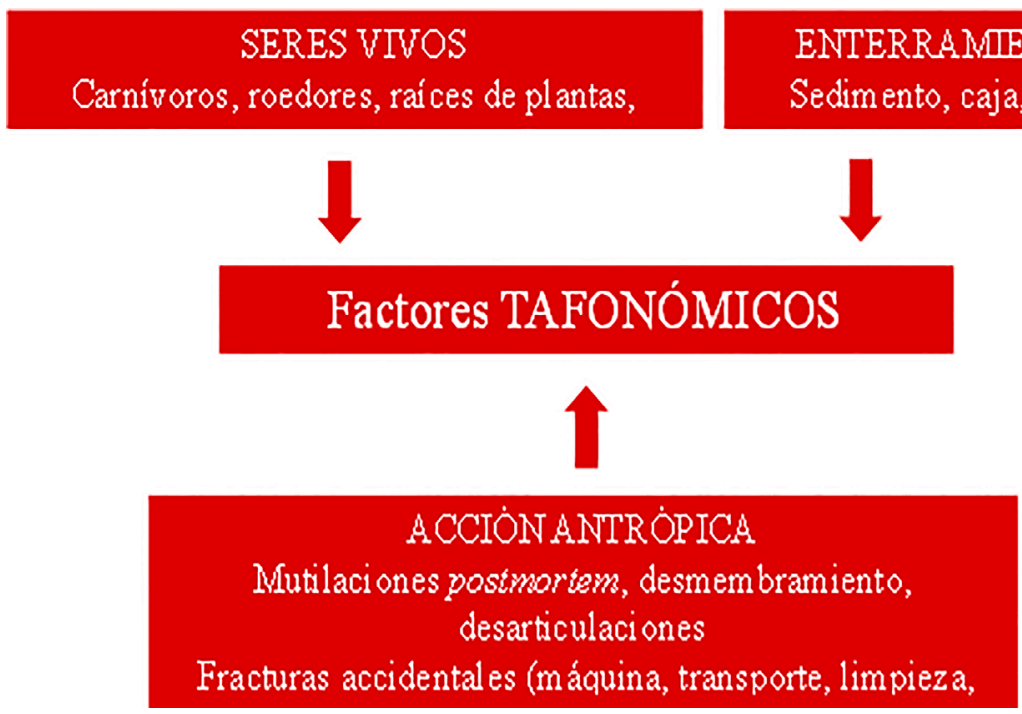

Fig. 6. Factores tafonómicos. 
En La Magdalena se han encontrado algunas de las lesiones anteriormente descritas.

Un claro ejemplo de acción antrópica es una de las tumbas campaniformes (Figura 07) en donde se han encontrado los esqueletos de dos mujeres, una adulta y otra madura, en conexión anatómica y, debajo de ellas, huesos dispersos de otra mujer también adulta. Las tres carecían de cráneo y de las primeras vértebras cervicales (C1 a C4). No se ha podido determinar la presencia de marcas de cortes en la vértebra C5, debido al mal estado de conservación del hueso. Es interesante destacar que de los 10 individuos campaniformes, únicamente en 2 casos conservan el cráneo la mujer 4467, y un niño el 4307. Parece que los campaniformes tenían algún tipo de ritual que consistía en el culto a los antepasados, centrado en los cráneos a modo de reliquia.

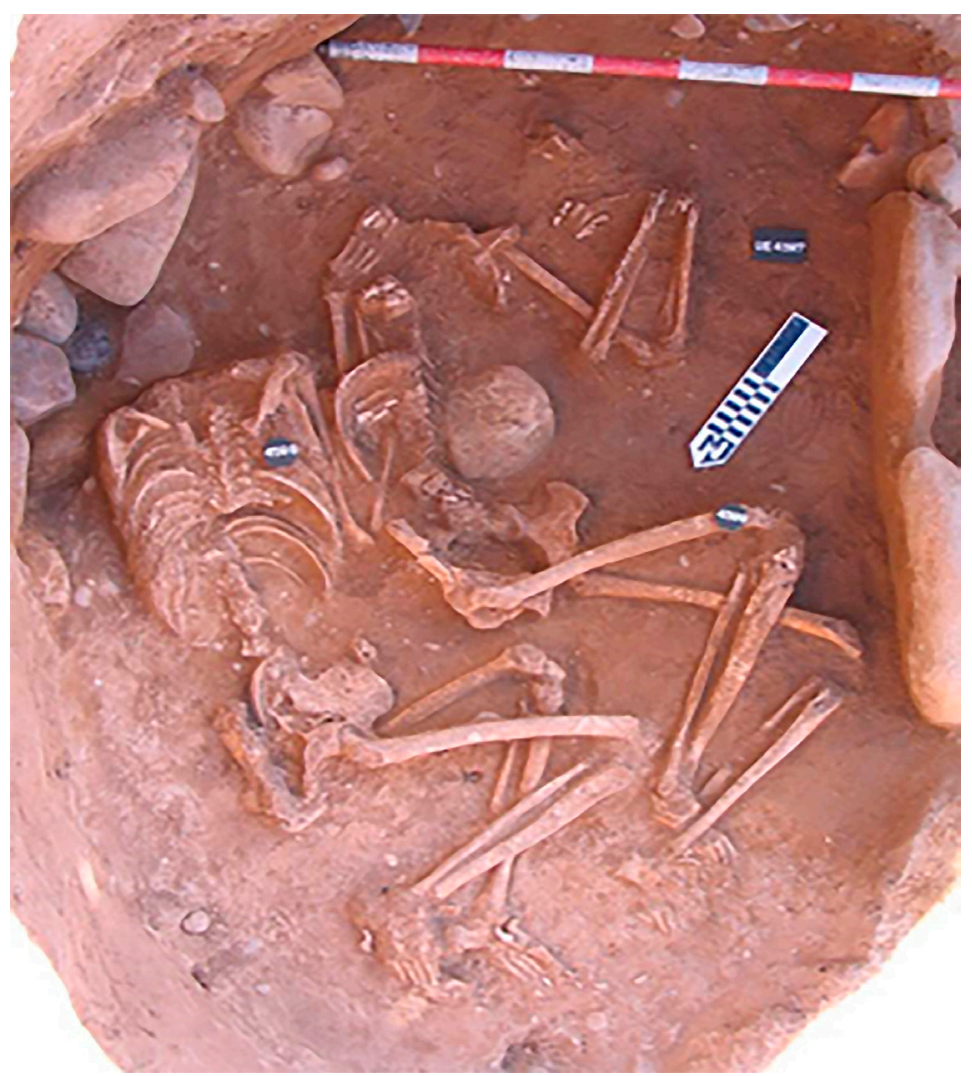

Fig. 7. La Magdalena: tumba campaniforme 4600, individuos 4598 y 4599.

Entre las alteraciones producidas por seres vivos, en La Magdalena se han descrito casos en los que los huesos estaban afectados por las raíces de plantas como los que aparecen en la Figura 08, en ocasiones penetrando en el interior 
del hueso y rompiéndolo, y en otras, dejando su impronta o tiñéndolo, como se observa en la figura 09 (Gómez et al., 2014).
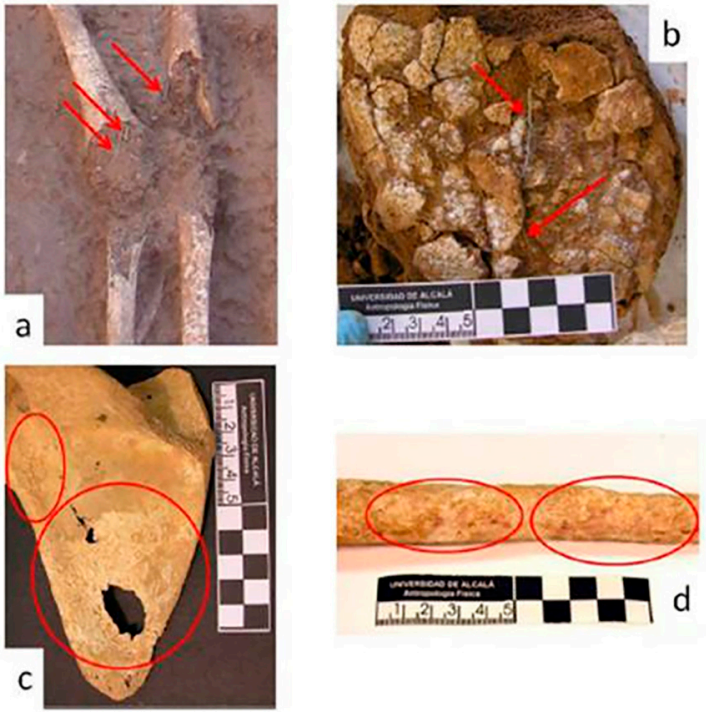

Fig. 8. Efecto de las raíces sobre los huesos de varios individuos de La Magdalena (araíces en el interior de los huesos largos de las piernas, b- en el interior de un cráneo, c- marcas radiculares afectando a un omóplato y d- manchas violáceas dejadas por las raíces sobre el hueso).
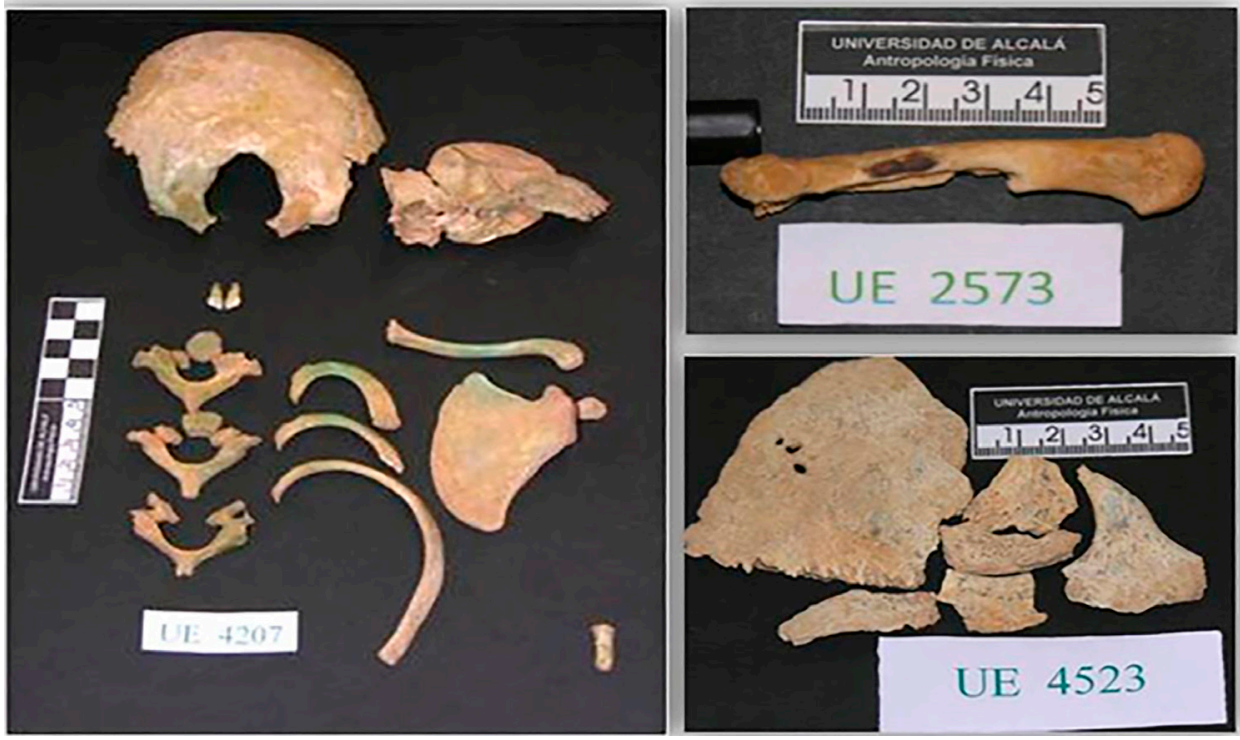

Fig. 9. Efectos del óxido de cobre (individuo 4207), el óxido de hierro (individuo 2573) y los hongos (individuo 4523) sobre los huesos de varios individuos de La Magdalena. 
En otras ocasiones fueron las sustancias químicas presentes en el suelo las que produjeron, en este caso, pérdidas de tejido óseo, afectando sobre todo al periostio (figura 10).

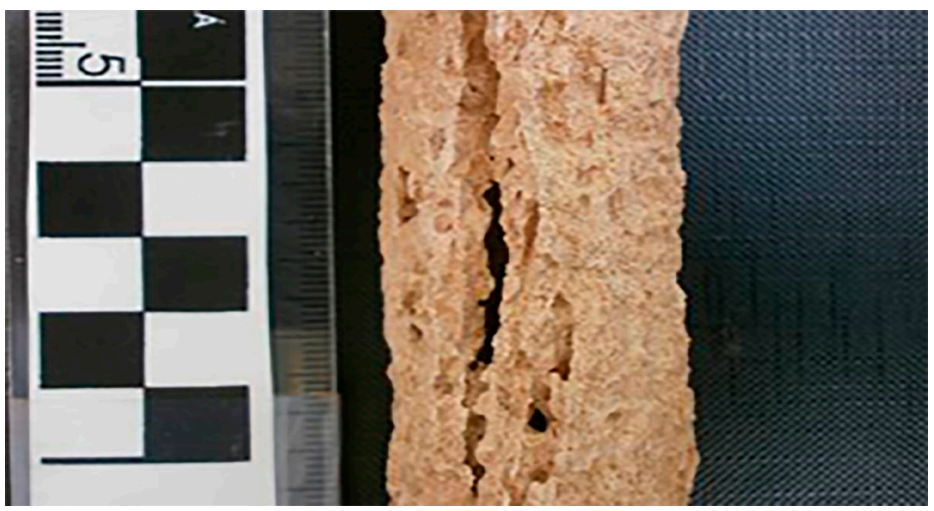

Fig. 10. Fragmento de diáfisis del individuo calcolítico de La Magdalena $\mathrm{n}^{\circ} 4053$, cuyos huesos estaban afectados por un proceso de disolución química debido a la presencia de carbonatos en el terreno.

Entre las conclusiones tafonómicas obtenidas hasta la redacción del presente artículo, se puede destacar, el bajo porcentaje de conservación para los restos esqueléticos humanos exhumados en La Magdalena, en donde más del 65\% de los individuos excavados estaban afectados por uno o más factores tafonómicos, siendo los mayoritarios la afectación por hongos y las antrópicas producidas en la fase de actuación del raspado del terreno por la maquinaria correspondiente (Figura 11). De los 182 individuos estudiados, 119 están afectados por al menos un factor tafonómico.

\begin{tabular}{|c|c|c|}
\hline $\begin{array}{c}\text { FACTORES } \\
\text { TAFONÓMICOS }\end{array}$ & $\begin{array}{c}\text { \% sobre el total de } \\
\text { individuos }\end{array}$ & $\begin{array}{c}\text { \% sobre los individuos que } \\
\text { presentan lesiones por } \\
\text { factores tafonómicos }\end{array}$ \\
\hline Raices & 7,10 & 10,92 \\
\hline Concreciones calcáreas & 14,75 & 22,69 \\
\hline Hierro & 10,38 & 15,97 \\
\hline Cobre & 8,74 & 13,45 \\
\hline Hongos & 30,05 & 46,22 \\
\hline Arrasados por la máquina & Sobre 223 individuos & \\
\hline
\end{tabular}

Fig. 11. Factores tafonómicos que han producido alteraciones en los huesos de los individuos de La Magdalena. 


\section{Huesos de animales}

La determinación de si los restos esqueléticos que se excavan en un yacimiento arqueológico son humanos, de otro animal, o incluso se trata de otro tipo de material, resulta sencilla cuando se cuenta con un antropólogo en el equipo y los huesos están más o menos completos. En ese caso, las diferencias morfológicas, así como las áreas de inserciones musculares, la curvatura de los huesos largos o el espesor del hueso compacto, suelen ser suficientes características para la determinación. Pero cuando el fragmento es pequeño y no fácilmente reconocible por su morfología, hay que recurrir a técnicas radiográficas, histológicas, inmunológicas o al ADN. La determinación proteica mediante antisuero humano es la más frecuente en los laboratorios biológicos, para ello se somete al tejido óseo en estudio a la reacción con antisuero humano, si hay aglutinación indica que es humano y si no la hay que no lo es. En caso de querer determinar la especie se necesitaría disponer de antisuero de perro, caballo, etc.

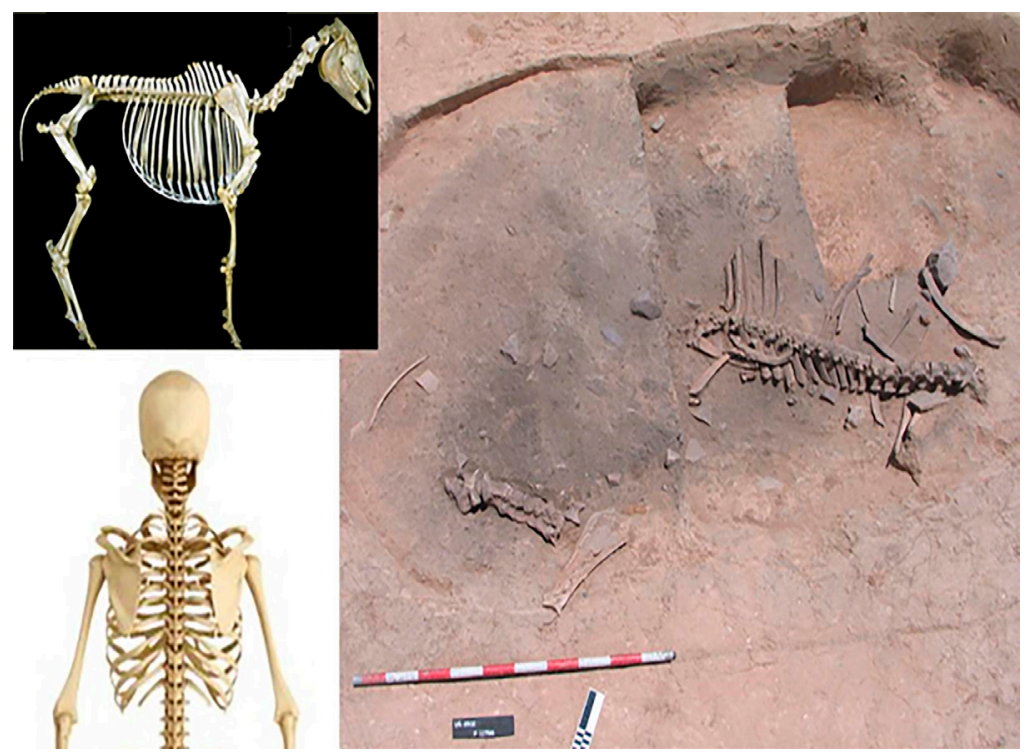

Fig. 12. La Magdalena, restos esqueléticos de un équido y su comparación anatómica con la morfología de un caballo y el hombre.

En el yacimiento de La Magdalena se han encontrado restos esqueléticos de varios animales. Algunos de ellos estaban en distintos basureros: conejos (entre 8 y 10 individuos todos inmaduros), cerdos, ovejas, cabras, perros, ciervos y cabaIlos. En la Figura 12 se pueden ver los restos esqueléticos de un équido, en cierta conexión anatómica. Únicamente se han conservado algunas partes del tórax en conexión anatómica, una escápula y el fragmento de una pata con la pezuña, lo que indica que este animal no fue consumido en su totalidad. 
En la Magdalena se ha constatado la ausencia de restos de animales asociados a las tumbas con restos humanos, salvo en el caso de tres enterramientos de época bajoimperial, uno que contenía los restos de un individuo infantil, un niño de aproximadamente 8 años (el 5288), otro que contenía los restos de un varón adulto, el 5217, y un tercero, que contenía a un varón adulto, el 7024. En la Figura 13 se puede ver al individuo 5288, en decúbito supino, con piernas extendidas y los brazos a lo largo del cuerpo. Hacia la mitad de su tibia derecha se encontraron los restos esqueléticos de un ave, entre los que se encuentra la fúrcula (hueso en forma de horquilla típico de las aves, formado por la fusión de las dos clavículas).

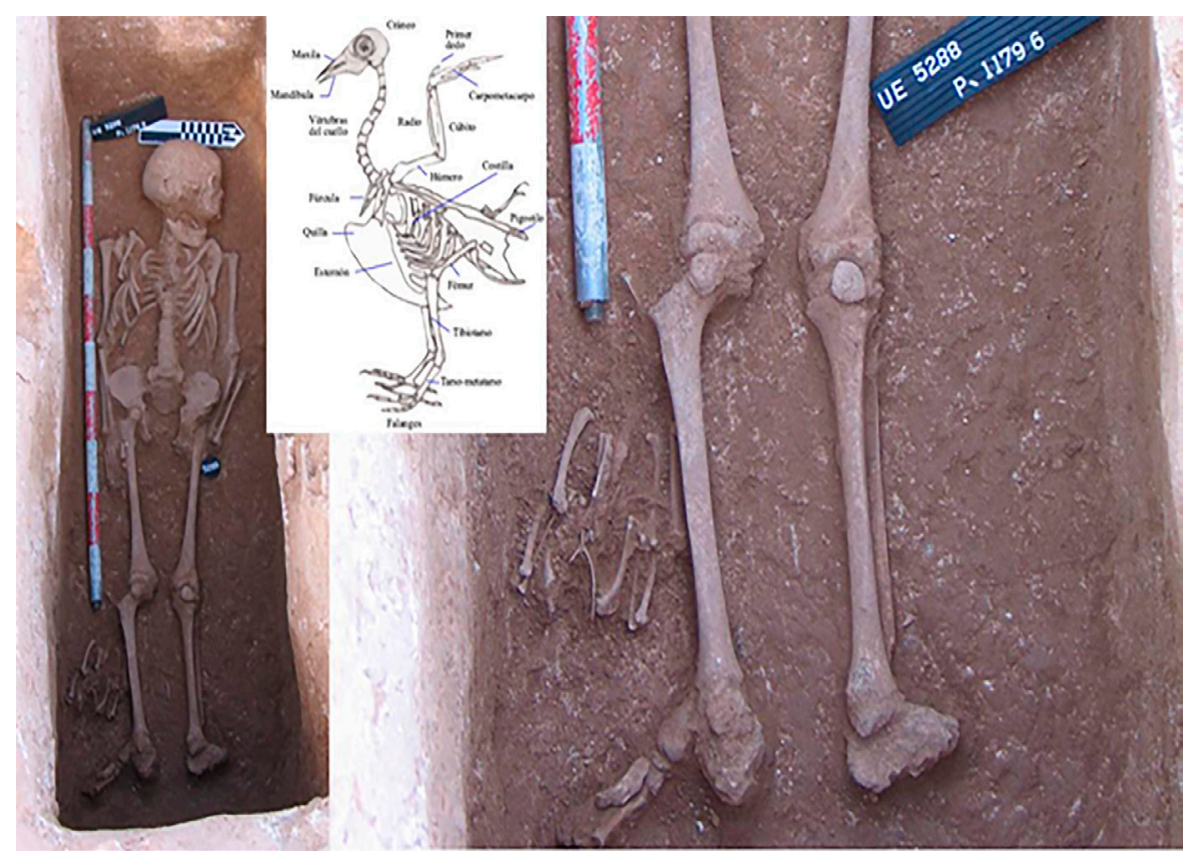

Fig. 13. Enterramiento bajoimperial 5288. Esqueleto de un individuo infantil II y restos de un ave junto a su tibia derecha.

\section{Número mínimo de individuos}

Como ya se ha indicado anteriormente, las excavaciones en La Magdalena han puesto de manifiesto, la presencia de varias necrópolis que indican que esta zona estuvo habitada por grupos campaniformes y del bronce, y muy posteriormente, por poblaciones hispanorromanas, entre los siglos I y VI d.C., e hispanovisigodas, entre los siglos VII al VIII d.C. En cada uno de estos grupos se determinación el número mínimo de individuos, que se estableció atendiendo al número de huesos que se repiten y a criterios como la edad o el sexo. Un claro ejemplo de cómo se llevó a cabo dicha determinación, es la tumba campaniforme 5010. En ella 
se encontraron los huesos de 4 piernas, dos derechas y dos izquierdas y además aparecían 2 mandíbulas, lo que llevó a estimar la presencia de al menos dos individuos, que tras su estudio resultaron ser adultos y probablemente masculinos (por la morfología mandibular). Otro ejemplo es la tumba bajoimperial 4264, en donde se encontró un individuo adulto en conexión anatómica, el 4268 (que resultó ser un varón maduro) y los restos desarticulados correspondientes a otro individuo adulto maduro, el 4266, que fueron sometidos a "reducción" para enterrar al segundo (Figura 14).

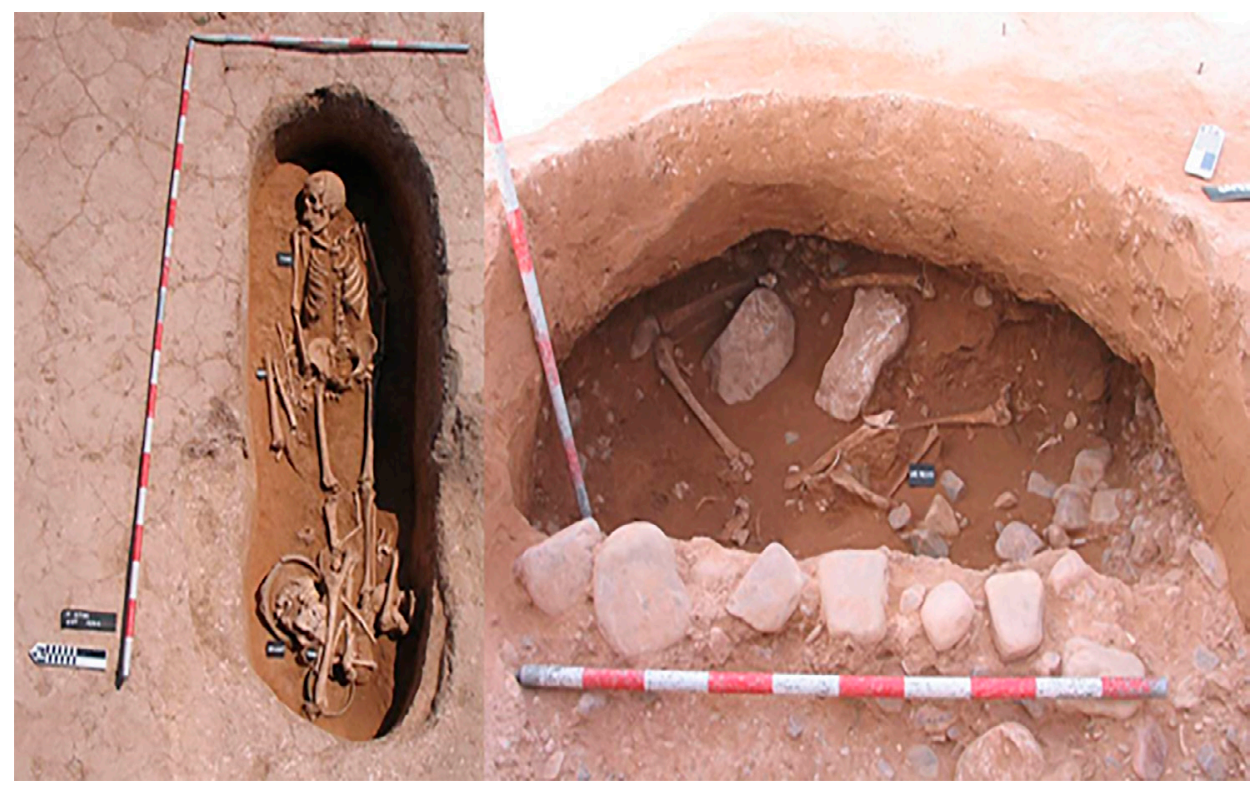

Fig. 14. Izquierda: tumba 4264 bajoimperial (individuos 4268 y 4266) y derecha: tumba 5005 campaniforme (individuos 5010a y 5010b).

El estudio antropológico ha permitido estimar el número mínimo de individuos, así como el sexo y la edad de los mismos, para lo cual se han seguido los criterios recogidos en los manuales de Krenzer (2006) y Ubelaker (2007). Al momento de la presente redacción se ha determinado la presencia de 223 individuos, de los cuales la mayoría son hispanorromanos de época bajoimperial (Figura 15).

Los datos sobre la estructura de estos grupos humanos (Figura 16) atendiendo al sexo de los individuos, indica una proporción de sexos bastante equilibrada para todos los periodos analizados. Por otro lado, es de destacar el alto porcentaje de individuos en los cuales y debido a las malas condiciones de preservación, no se pudo determinar el sexo, siendo extremo este valor para el grupo de hispanovisigodos (10 individuos están en tumbas y 12 en basureros). La aplicación de las técnicas moleculares, en concreto el estudio del gen de la amelogenina, permiti- 
ría: 1) verificar la determinación del sexo morfológico y 2) bajar el porcentaje de alofisos.

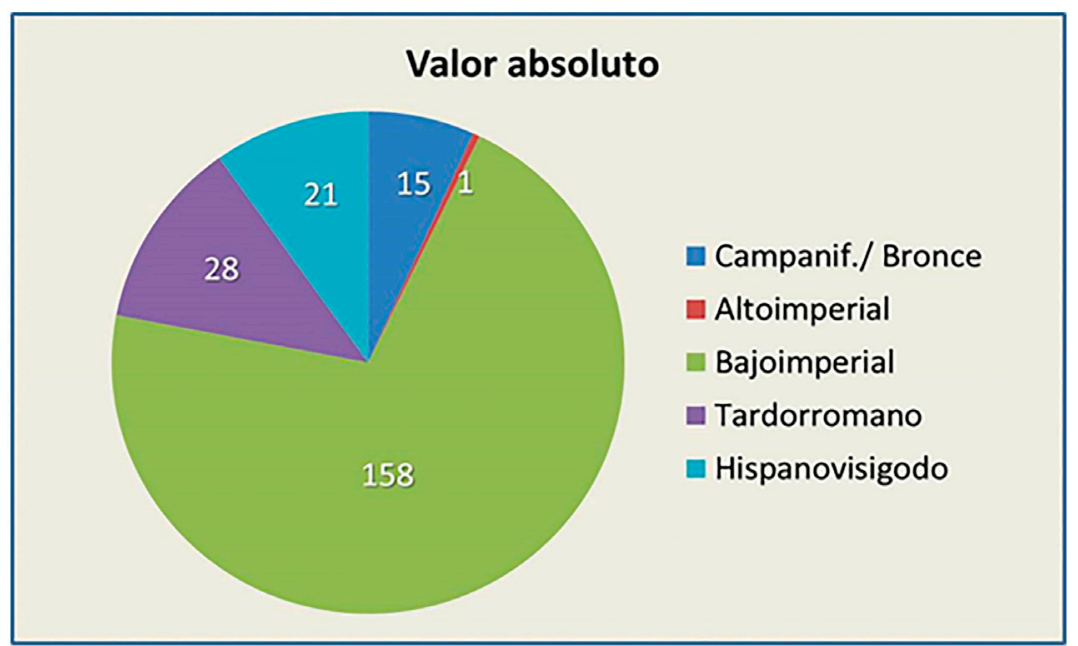

Fig. 15. Número mínimo de individuos excavados en las necrópolis de La Magdalena.

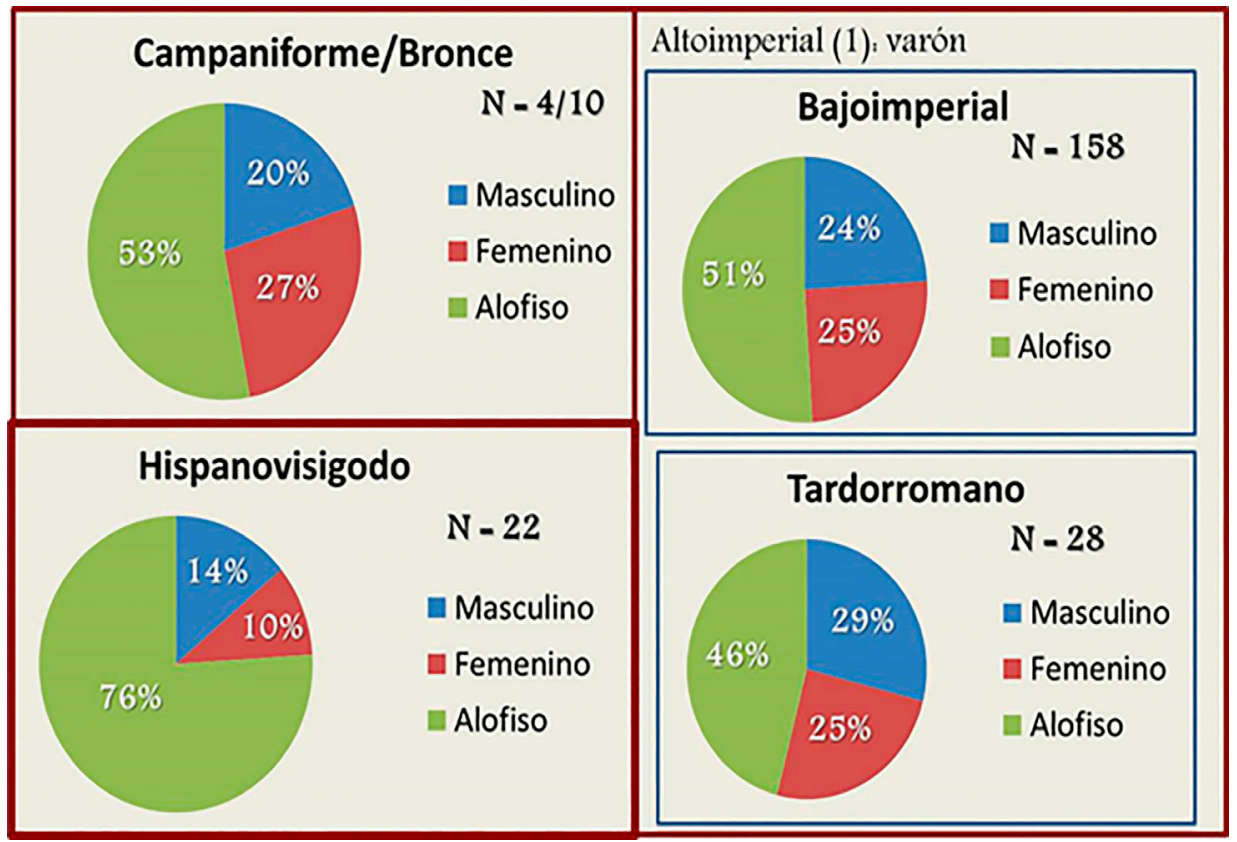

Fig. 16. Distribución por sexos de los individuos excavados en las necrópolis de La Magdalena. 
La edad no se pudo determinar en todos los individuos, únicamente fue posible en 9 individuos del campaniforme/bronce, 1 altoimperial, 137 bajoimperiales, 19 tardorromanos y 9 hispanovisigodos (Figura 17). La muestra de mayor tamaño es la de los bajoimperiales y presenta unos resultados bastante coherentes, con una elevada mortalidad en las primeras edades, que va disminuyendo hasta llegar a la edad adulta en donde aumenta nuevamente la mortalidad. Parece que la mayoría de los individuos no sobrepasaba los cuarenta años aunque unos pocos llegaron a sobrepasar los 60. La interpretación de lo que ocurrió en el resto de los periodos resulta difícil y arriesgada debido al bajo tamaño de la muestra.

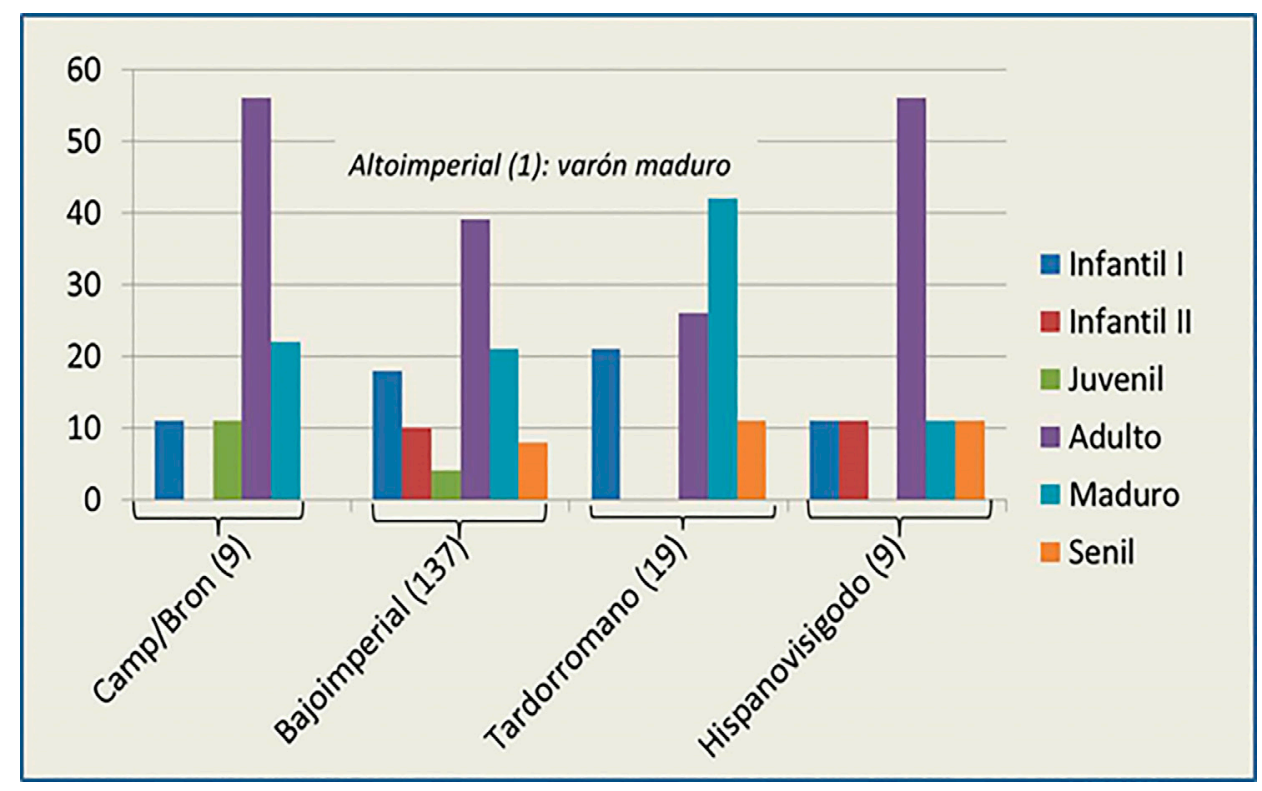

Fig. 17. Distribución por edades de los individuos excavados en las necrópolis de La Magdalena.

\section{Morfología}

En cuanto a la morfología de estas gentes, no se ha obtenido demasiada información por el momento. Unos primeros datos los ofrece el trabajo de Pacheco et al. (2020). Cabrera et al. (2014) estudiaron el grupo campaniforme/bronce y Díaz et al. (2014) los bajoimperiales y tardorromanos.

Entre los caracteres morfológicos, la estatura es uno de los más estudiados en Antropología al estar determinada genéticamente pero, al mismo tiempo, ser muy ecosensible. En La Magdalena se ha podido estimar la estatura para tres de los periodos analizados, bajoimperial, tardorromano e hispanovisigodo y se ha encontrado que la estatura no difiere mucho entre ellos. Esto podría indicar una continuidad de los grupos humanos a lo largo del tiempo. Los resultados son los siguientes: 
- Varones: bajoimperiales (166.58 - 168,45 cm), tardorromanos $(168,44$ $172,53 \mathrm{~cm})$ e hispanovisigodos $(155,52-167,58 \mathrm{~cm})$.

- Mujeres: bajoimperiales (157,73 - 161,06 cm), tardorromanas $(158,60$ $162,03 \mathrm{~cm})$ e hispanovisigodas $(156,21$ - 161,61 cm).

El conocimiento de la morfología facial es otro de los retos a los que se enfrenta el equipo de investigación de La Magdalena. Una primera aproximación al tema ha sido la reconstrucción facial o, más bien, aproximación a la fisonomía que debió tener en vida uno de los individuos excavados en el yacimiento. Rivilla et al. (2014) publicaron la reconstrucción facial de un esqueleto humano bajoimperial del segundo tercio del siglo III d.C. (individuo 4109) cuyos huesos estaban en excelente estado de conservación. Se trata de un enterramiento primario, en fosa simple, en donde además de los restos humanos, se encontraron restos de cerámica, clavos y adornos personales (tobillera, restos de arandelas de bronce y cuentas de pasta vítrea). La metodología fue la siguiente (Figura 18): 1) en primer lugar se obtuvo una réplica del cráneo, para lo cual se contó con la colaboración del Área de Fotografía e Infografía del Servicio de Criminalística de la Guardia Civil, quienes escanearon el cráneo y la mandíbula con un láser escáner (la captura digital se realizó con el software RapidForm, versión 2006) y obtuvieron el molde impreso del cráneo y la mandíbula virtual con una impresora 3D; 2) se determinaron los puntos craneométricos y el espesores de los tejidos blandos en cada uno de ellos; 3) se diagnosticó la edad, el sexo, el origen ancestral y la robustez del individuo (mujer joven de entre 20 y 24 años, de complexión grácil y de origen caucásico).

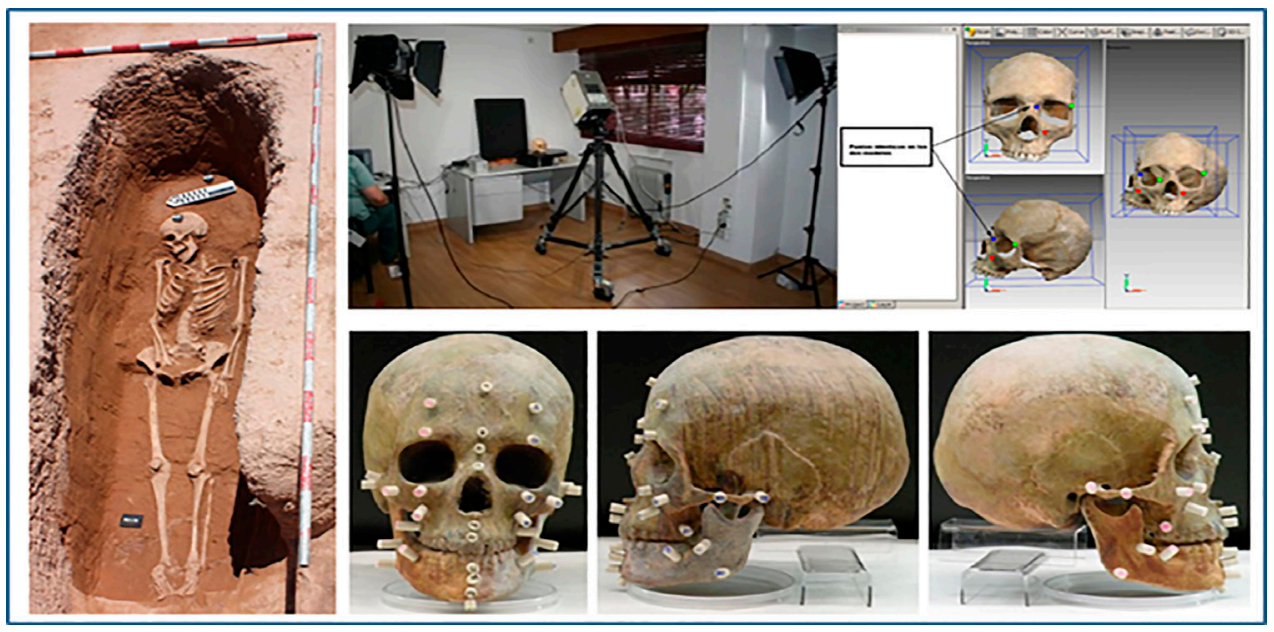

Fig. 18. Tumba del individuo 4109 (Magdalena III: segundo tercio siglo III d.C.) y detalles del proceso de captura del cráneo, la localización de los puntos craneométricos y establecimiento en los mismos de los espesores de los tejidos blandos. 
Seguidamente y basándose en las investigaciones científicas que permiten determinar los caracteres morfológicos de la cara (Wilkinson, 2004) se estableció la morfología más probable que debió tener esta mujer romana (Figura 18).

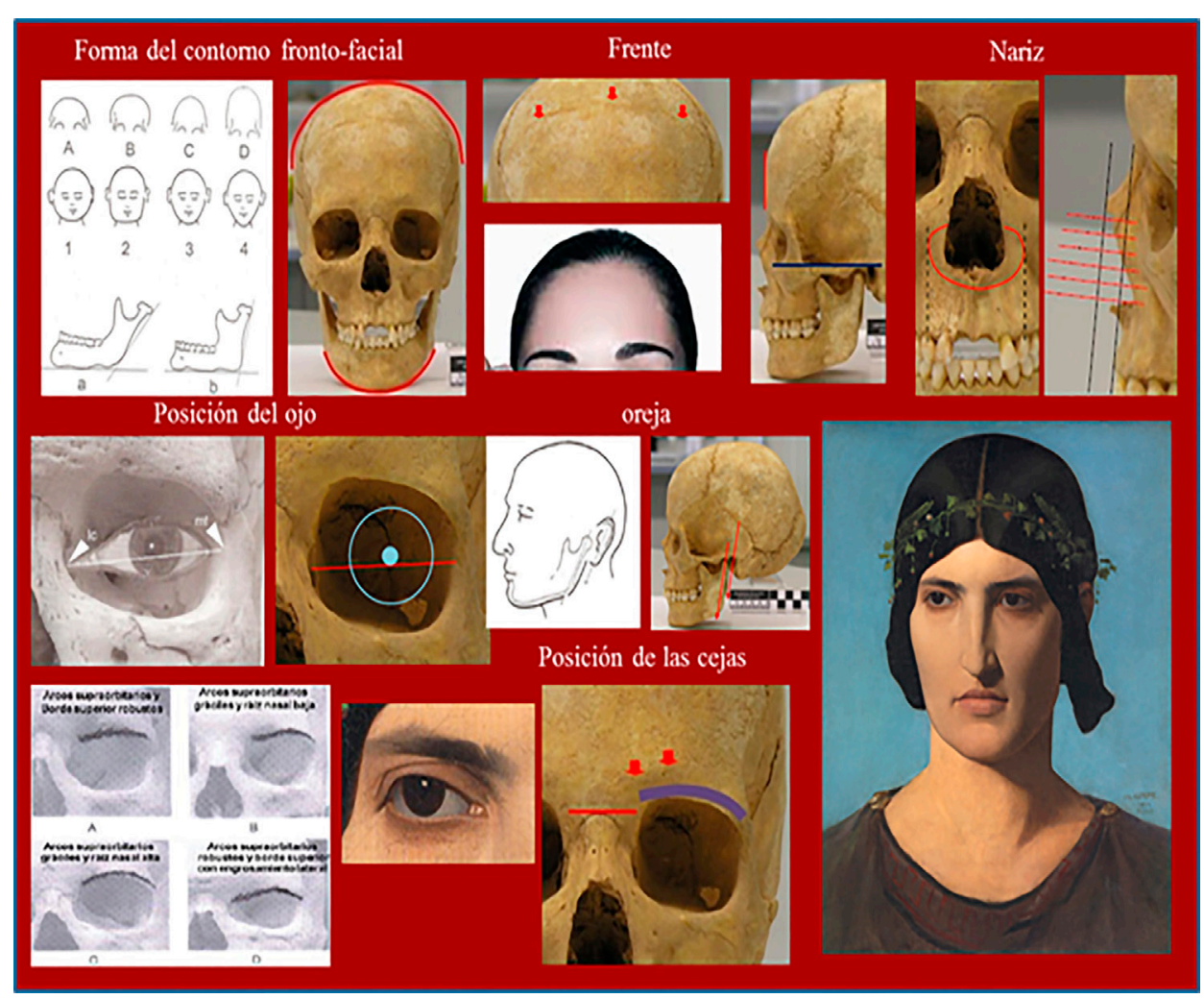

Fig. 19. Aproximación fisonómica de la mujer romana 4109 excavada en el yacimiento de La Magdalena.

\section{Hacia dónde debemos dirigirnos}

Desde hace ya algunos años venimos observando cómo se está desarrollando una construcción de la Ciencia basada en la acción participativa en rango de igualdad de un alto número de disciplinas, teniendo como eje vertebrador la necesidad de enfrentarse a la resolución de cuestiones complejas.

Desde la óptica tanto de las Antropologías como de la Historia, observamos una disolución de los límites de sus competencias, de tal manera que cada vez es más un hecho la imbricación entre diversas disciplinas que aportan conocimiento y discusión ante la interpretación de cualquier fenómeno que ataña al hombre tanto físico como social y cultural. 
La aplicación de un modelo transdisciplinar de investigación comporta una nueva forma de enfrentarnos a la problemática del estudio de las diversas facetas que representa tanto el individuo como el colectivo humano. Todas aquellas disciplinas que tengan algún elemento que aportar a la resolución de un problema concreto (resolver la totalidad es una entelequia) se integran en rango de igualdad dentro del discurso interpretativo.

Si pensásemos en una figura que represente la transdisciplinariedad, podríamos referir una figura poliédrica. En su variante regular (con caras y ángulos iguales) nos indicaría que todas las disciplinas que participan en la explicación de un problema planteado lo hacen en régimen de plena igualdad y equilibrio. Sin embargo, por lo general nos encontramos ante poliedros irregulares (con caras o ángulos desiguales), donde las distintas disciplinas que participan en la interpretación del problema planteado aportan toda la información referida al hecho, aunque algunas disciplinas presentan un mayor rango de datos, que no de aporte interpretativo, que otras.

En este sentido, desde hace varios decenios, se están dando pasos que, desde diferentes direcciones, se alejan progresivamente del determinismo disciplinar que encorseta la producción del conocimiento del pasado, abriendo la Arqueología a una interacción con otras disciplinas, siendo la Antropología física una de las primeras en potenciar esta colaboración participativa. Y dentro de ésta, la Antropoarqueología/Arqueoantropología funeraria y forense ha ido abriendo este camino.

Es importante dejar claro que la transdisciplinariedad no se limita a la investigación cooperativa o a la integración disciplinaria en torno a un tema de investigación (que ya definimos como interdisciplinar o multidisciplinar), sino que se ocupa de combatir los principales peligros de la disciplinariedad, tales como la parcelación, el aislamiento y la simplificación del conocimiento; así como la incomunicación con sus contrarios que genera el saber-poder disciplinario.

La visión transdisciplinar persigue un conocimiento global, integral y complejo. Une conocimientos en vez de separarlos, al tiempo que propone considerar una realidad multidimensional que reemplaza la realidad unidimensional del pensamiento clásico (Sanchez Yustos, 2014: 14).

Bajo estos parámetros, hemos de considerar que el trabajo que aquí presentamos, no es sino un primer apunte en relación con la interactuación disciplinar para enfrentarnos al fenómeno vital de la muerte y a la sistemática del estudio e interpretación parcial de cada uno de los elementos que en ella convergen, tanto desde una óptica física como socio-cultural.

Igual que la dualidad vida/muerte es una constante en nuestra especie, la asunción de la muerte como hecho físico y psicosocial comprende desde la asunción del hecho, la comprensión del significado profundo y su explicación para el co- 
lectivo que vive el hecho fúnebre y la generación de modelos rituales (simples y complejos) que conectan ambas esferas del ser y del estar, generadoras de la cohesión mediante el recuerdo.

El estudio, tanto del fenómeno físico de la muerte, como del social, cultural e ideológico, conforman la base del complejo investigativo tanatológico, en el que se integrarían las diversas disciplinas científicas que sobre este fenómeno han de interactuar.

\section{Bibliografía}

ALCINA FRANCH, J.: Arqueología antropológica. Akal, Madrid, 1989.

ALIAGA ALMELA, R.: "Términos y conceptos para el estudio de las prácticas funerarias en Arqueología". Revista Historia Autónoma, 1, 2012: 13-20.

BEALS, R. y HOIJER, H.: Introducción a la antropología. Aguilar, Madrid, 1978.

BINFORD, L.R.: En busca del pasado. Crítica, Barcelona, 1988.

CABRERA JIMÉNEZ, C.M.; GALERA OLMO, V. y HERAS MARTÍNEZ, C.: "El campaniforme en la Submeseta Sur: estudio antropológico de los restos esqueléticos de La Magdalena I (Alcalá de Henares). IX Jornadas del Patrimonio Arqueológico en la Comunidad de Madrid, Alcalá de Henares, 2014, 127-135.

CHAPA BRUNET, T.: "La Arqueología de la Muerte: planteamientos, problemas y resultados". En Vaquerizo Gil (coord.), Arqueología de la Muerte: Metodología y Perspectivas actuales. Diputación Provincial, Córdoba, 1991, 13-38.

- "Aplicaciones de la Arqueología de la Muerte en la Prehistoria reciente de la Península Ibérica". Actas do $3^{\circ}$ Congresso de Arqueologia Peninsular, Vol. 5. Proto-Història da Peninsula Ibérica, Porto, ADECAP, 2000, 9-19.

- "Arqueología de la Muerte. Aspectos metodológicos", Anales de Arqueología Cordobesa, 17: 25-46, Universidad de Córdoba.

CRIADO BOADO, F.: Arqueológicas. La razón perdida, Bellaterra, Barcelona, 2012.

DÍAZ-GONZÁLEZ, MãE.; GÓMEZ-MORENO, F.; GALERA OLMO, V. y HERAS MARTÍNEZ, C.: "Los restos esqueléticos de las necrópolis bajoimperial y tardorromana de "La Magdalena» (Alcalá de Henares). Primeros datos desde la Antropología Física". VIII Jornadas del Patrimonio Arqueológico en la Comunidad de Madrid, Alcalá de Henares, 2014, 189-196.

DOMÍNGUEZ-RODRIGO, M.: "Arqueología neo-procesual: «Alive and kicking». Algunas reflexiones desde el Paleolítico". Complutum, 2008, 19 (1), 195-204.

FERNÁNDEZ MARTíNEZ, V.M.: Una Arqueología Crítica. Ciencia, ética y política en la construcción del pasado. Crítica, Barcelona, 2006. 
GÓMEZ-MORENO, F.; GALERA OLMO, V. y HERAS MARTÍNEZ, C.: "Primeros datos tafonómicos de dos necrópolis procedentes del yacimiento de La Magdalena (Alcalá de Henares, Madrid)". XVII Congreso de la Sociedad Española de Antropología Física, U. Barcelona, 2011: 204-213.

— "Primeros datos sobre las alteraciones por las raíces de los restos esqueléticos humanos de "La Magdalena», (Alcalá de Henares, Madrid)". XVIII Congreso de la Sociedad Española de Antropología Física, Bilbao, 2014, 133-147.

GONZÁLEZ RUIBAL, A.: "Hacia otra arqueología: diez propuestas". Complutum, 2012, 23 (2), 103-116.

HERAS MARTÍNEZ, C.; BASTIDA RAMÍREZ, A. y CORRALES PEVIDA, R.: “El conjunto industrial romano altoimperial de la finca "La Magdalena» (Alcalá de Henares): los alfares". I Congreso de la Sociedad de estudios de la cerámica antigua en Hispania, Cádiz-2011, Universidad de Cádiz y SECAH, 2013, 385398.

HERAS MARTÍNEZ, C.; BASTIDA RAMÍREZ, A. y GALERA OLMO, V.: "La fase campaniforme del yacimiento de La Magdalena (Alcalá de Henares, Madrid)". Yacimientos Calcolíticos con Campaniforme de la región de Madrid: nuevos estudios, Blasco, Liesau y Ríos (eds.), Patrimonio Arqueológico de Madrid, 6, UAM, Madrid, 2011, 17-21.

HERAS MARTÍNEZ, C.; BASTIDA RAMÍREZ, A. y GALERA OLMO, V.: "El conjunto industrial romano Altoimperial de "La Magdalena» II (Alcalá de Henares): Hornos, almacenes y conjuntos hidráulicos. VIII Jornadas del Patrimonio Arqueológico en la Comunidad de Madrid, Alcalá de Henares, 2014, 65-78.

HERAS MARTÍNEZ, C.; BASTIDA RAMÍREZ, A.; GALERA OLMO, V. y CORRALES PEVIDA, R.: "Necrópolis Bajoimperial y Tardorromana de «La Magdalena» III-IV (Alcalá de Henares): contextualización arqueológica". VIII Jornadas del Patrimonio Arqueológico en la Comunidad de Madrid, Alcalá de Henares, 2014, 79-92.

HERAS MARTÍNEZ, C.; CORRALES PEVIDA, R; BASTIDA RAMÍREZ, A.; SÁNCHEZ MEDINA, E. y GALERA OLMO, V.: " "Recuperando la muerte»: Las necrópolis de La Magdalena (Alcalá de Henares), entre el Calcolítico y la Hispania visigoda", El Patrimonio Complutense recuperado. Institución de Estudios Complutenses, Alcalá de Henares, 2014, 22-75.

HERAS MARTÍNEZ, C.; CUBAS MORERA, M. y BASTIDA RAMÍREZ, A.: "Signos y símbolos en el registro funerario: ajuares de la necrópolis Calcolítica con Campaniforme de "La Magdalena» I (Alcalá de Henares)". IX Jornadas del Patrimonio Arqueológico en la Comunidad de Madrid, Alcalá de Henares, 2014, 187-198.

HERAS, C.; GALERA, V. y BASTIDA, A.: "Enterramiento y ritual funerario en una necrópolis Calcolítica con Campaniforme en la Submeseta Sur. El yacimiento 
de "La Magdalena» I (Alcalá de Henares)". IX Jornadas del Patrimonio Arqueológico en la Comunidad de Madrid, Alcalá de Henares, 2014, 213-227.

KRENZER, U.: "Compendio de métodos antropológico forenses". Centro de análisis forense y ciencias aplicadas. Guatemala. 2006.

MONTÓN SUBÍAS, S. y ABEJEZ, L.J.: “¿Qué es esa cosa Ilamada Arqueología Histórica?". Complutum, 2015, 26 (1), 11-35.

MORIN, E. (2009): Introducción al pensamiento complejo, Gedisa. Madrid.

PACHECO REVILLA, G.; GÓMEZ-MORENO, F.; HERAS MARTÍNEZ, C.; BASTIDA RAMÍREZ, A. y DIGES QUIJADA, Y.: "Aproximación al análisis bioarqueológico de la necrópolis tardorromana excavada en la Parcela 11796 de Alcalá de Henares". XVI Congreso de la Sociedad Española de Antropología Física (Gutiérrez-Redomero, Sánchez y Galera, eds.), Alcalá de Henares, 2010, 549556.

REBATO, E.; SUSANNE, Ch.; CHIARELLI, B. (eds.): "Para comprender la Antropología Biológica. Evolución y Biología Humana". Verbo Divino, Navarra, 2005.

RIVILLA MATÉ, MaT.; GALERA OLMO, V.; HERAS MARTÍNEZ, C. y MARTÍNEZ MESONES, P.A.: "Necrópolis Bajoimperial y Tardorromana de "La Magdalena» III (Alcalá de Henares): Reconstrucción facial del individuo 4109". VIII Jornadas del Patrimonio Arqueológico en la Comunidad de Madrid, Alcalá de Henares, 2014, 379-385.

RUIZ ZAPATERO, G y CHAPA, T.: "La Arqueología de la Muerte: Perspectivas teórico-metodológicas". Burillo Mozota, F. (coord.): Necrópolis Celtibéricas. II Simposio sobre los Celtíberos, 1990, 357-372.

SÁNCHEZ YUSTOS, P.: "Los márgenes del pasado. La producción transdisciplinar del saber arqueológico". Complutum, 2014, 24 (1), 9-16.

UBELAKER, D.: Enterramientos humanos: excavación, análisis, interpretación. Munibe, suplemento 24, Sociedad Aranzadi, 2007.

WILKINSON, C.: Forensic Facial Reconstruction. Cambridge University Press, Cambridge, Reino Unido, 2004. 
